\title{
Application of Mobile Learning System in Operating System Course
}

\author{
Lingling Guo, Yu Fu, Xiaozhe Yin, Man Yuan, Fangzhou Zhang, Juntao Gao \\ School of Computer \& Information Technology, Northeast Petroleum University, Daqing, China \\ Email: rainmanqing@yahoo.com.cn
}

Received March 18, 2013; revised April 17, 2013; accepted May 7, 2013

Copyright (C) 2013 Lingling Guo et al. This is an open access article distributed under the Creative Commons Attribution License, which permits unrestricted use, distribution, and reproduction in any medium, provided the original work is properly cited.

\begin{abstract}
With the rapid development of mobile communication and computer network technologies, the new mobile learning mode has been accepted by more and more people. In this paper, taking the learning system under mobile environment and from the perspective of necessary theoretic knowledge and relative technologies for mobile learning, the structural frame of the mobile learning system was discussed and constructed. According to this structural frame, the learning system under mobile environment was designed and applied into the OS course.
\end{abstract}

Keywords: Mobile Communication Technology; Mobile Learning; Operating System

\section{Introduction}

With the rapid development of mobile communication and computer network technologies, as well as the combination of computer network, telecommunication network and cable TV network, the Internet is entering the mobile Internet age. People can anywhere and anytime connect to the Internet for such activities as communication, learning, office work, entertainment and so on, breaking through the limitations of time and space. With the high-speed development of technologies and the consequent huge effect on education career, there occurs enormous change in both traditional teaching and learning mode. Therefore, the Internet based remote education rises and advances rapidly. On January 7th, 2009, MIIT offered the 3G full-service licenses to China Telecom, China Unicom and China Mobile, which indicates that China has fully embraced the 3G age. The arrival of 3G age promotes the development of informatization of human beings' society and quickens the pace of education informatization, so the learning mode has also come into an epoch-making innovation period [1]. The society we now live in is an information society, which has come up with brand-new capability requirements for talents. Traditional education has not been able to meet this requirement at all. However, M-learning is just a new learning mode which appears at this background following Elearning. The rise of M-learning brings new opportunities for the development of higher education in the information society.
International remote education authority and Ireland education technology expert Doctor Keegan put forward that the remote education has experienced three important stages, i.e. D-learning, E-learning and M-learning. Remote education now is undergoing great changes, and Doctor Keegan think that M-learning represents the future of remote education. The M-learning education mode provides a new idea to the reform of higher education. The computer science and technology major in our university is a national level comprehensive pilot reform and provincial level key major, into which the new concept of M-learning is introduced, and the major has very important significance to both the mode reform of education and the ability and quality cultivation of talents.

\section{Research Status}

Nowadays, many countries around the world have started to carry out studies on M-learning, which firstly began in America. In 1994, Carnegie Mellon University did research on a project called wireless Andrew [2], which make people in the campus be able to freely enjoy the convenience of M-learning based on wireless communication technology. Hereafter, various countries began to carry out M-learning studies, and experiments for evaluating the effectiveness of short message service being applied in education and teaching were done in Kingston University [3]. In Finland, University of Helsinki uses short message service in teachers' trainings and plans to use MMS technology in education and teaching in the 
following researches where digital images are generated and transmitted by mobile device [4]. University of Birmingham in England is established in the orientation of future education, and research group has now developed a kind of M-learning tool for 9 to 10 year old children with satisfactory test results [5-6]. University of Oslo in Norway has done the Know MOBILE research project, which allows medical major students to do experiments for PBL study, and the project indicates that it is necessary to instruct and train students appropriately before usage [7]. University of Tampere in Finland has developed an M-learning system called XTask aiming at collaborative learning, which can be well extended and is easy to use [8]. It can be seen from the summary of Meducation research projects abroad, their researches on M-learning are now in the positive discovering and effective trying stage. However, large-scale application experiments and popularization tests have not been carried out [9]. Learning resources which run on computers are now transferred to mobile devices because they have such characteristics as convenient, portable, easy to interact, omnipresent network covering and so on.

In recent years, domestic scholars are doing researches on relative contents and basic techniques of pervasive computing one after another. Since 1999, Tsinghua university has began to do researches on pervasive computing, Smart Classroom developed by human-computer interaction and media integration research institution has made in-depth discussions on theory and practice of pervasive computing from the perspective of human-computer interaction and systems' supporting software [10]; University of Electronic Science and Technology of China has also carried out monographic researches on concepts of pervasive computing and their embedded applications; Peking University has done some exploratory work on the improvement of handhold mobile device interactions [11]. On March 23rd, 2006 the Research on Application of Handhold Network Learning System in Subject Teaching held by Education and Technology Institute of Beijing Normal University received official approval [12].

Through introducing domestic research project on Mlearning, it can be found that although some achievements have been obtained when compared to developed Europe and America regions the domestic M-learning research level is still low and the research scale is small, too. However, the domestic M-learning researches are now developing gradually. There still exist such problems in M-learning platforms as simple and deficient learning resources, unstable learning systems, imperfect learning functions, bad operations and interactions and so on. These problems, however, will be improved in the future because M-learning is still a new thing and especially because that the $3 \mathrm{G}$ technology is now developing.

\section{Relative Techniques of M-Learning}

Development of M-learning system includes Mobile Terminal, Wireless Communication Technology and Mobile Internet Technology [13]. The relationship between technologies in the M-learning system is shown in Figure 1.

Development of these technologies facilitates the acquisition and disposal of information resources, which directly promotes the development of M-learning.

\section{Design of M-Learning System Based on OS Course}

M-learning system platform is designed according to computer major course Operation System, so that students can learn this course anytime and anywhere; this is also a beneficial attempt for M-learning teaching mode.

\subsection{General Design of M-Learning System}

The structure of this M-learning system is made up of presentation layer, network layer, service logic layer and data layer in successive low-to-high order, shown in Figure 2. The present layer is located in client-side, network layer is based on mobile communication network and internet, and service logic layer and data layer are located in service end.

\subsection{Structure Design of M-Learning System}

By using M-learning system, teachers can make some necessary supplement to the contents of the courses. Meanwhile, students are able to make discussions and exchanges with the resources and questions on the system to improve their learning efficiencies. Each function mode of the system is seriously designed according to the analyses of system functions, shown in Figure 3.

From the function mode figure of M-learning system, it can be seen that, this system sufficiently shows several important teaching modes:

1) Learning contents and post tests can make students learn selectively and autonomously according to their own characteristics and learning levels, and can allow them to find suitable research orientations and interested research fields in the technology advances, following the individual and autonomous learning mode;

2) Project cooperation gives full play to group cooperation learning mode and each member of the group is motivated. In order to make the project develop successfully, each member gives advice and suggestions and makes his/her own contributions;

3) With the strength of micro-blog and interaction section, the interaction part allows students to give feedback timely for discussions and exchanges, which accords with the social learning mode in M-learning.

In view of adverse factors of performances, display 


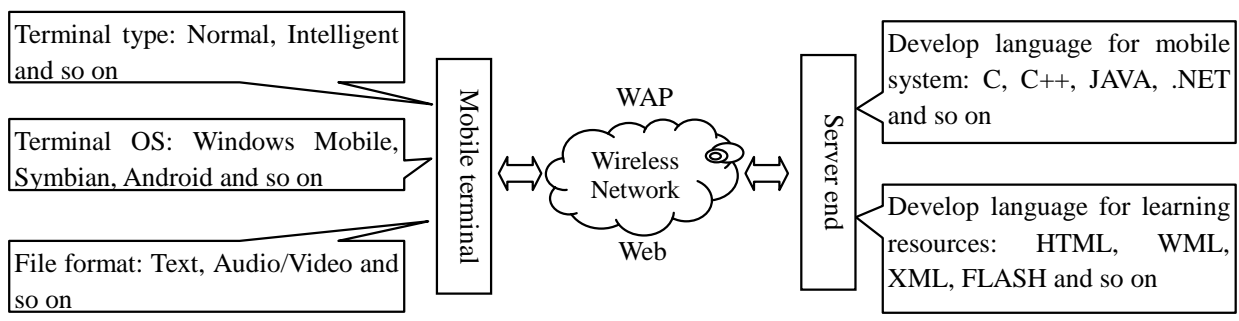

Figure 1. Relationship between relative technologies in the M-learning system.

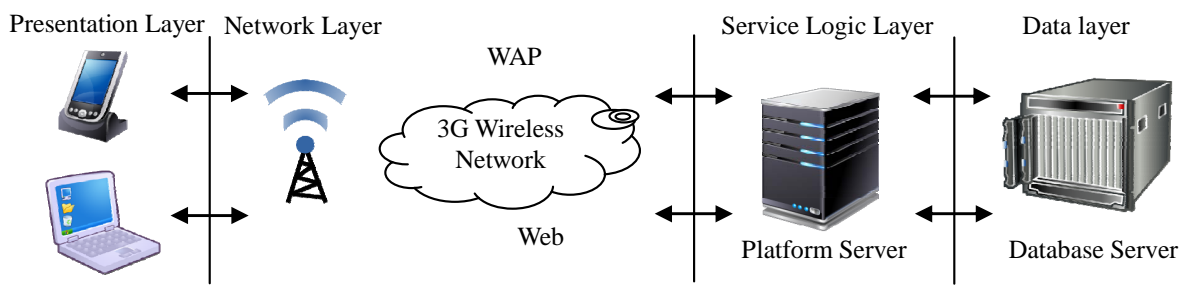

Figure 2. Structure of M-learning system for OS course.

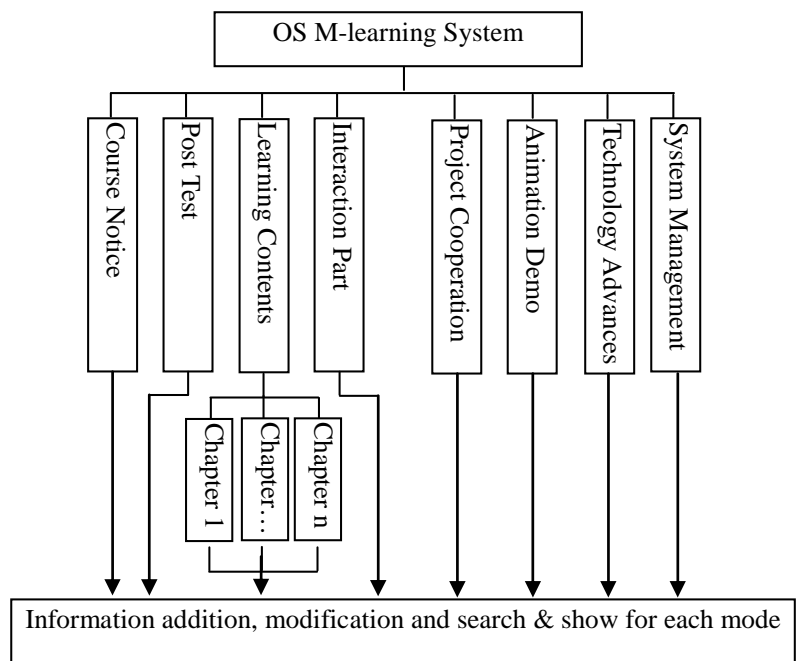

Figure 3. Function modes of M-learning system of OS course.

screens and inconvenient entering of such mobile devices as $3 \mathrm{G}$ mobile phones etc, there are two kinds of browse learning platforms which are based on Internet Web technology and small screen WAP 2.0 technology respectively at the system entrance. This allows students to choose the most suitable learning modes according to situations that they are in.

The structure of M-learning system is based on B/S technology, and students can directly get access to the mobile platform through browser to learn. Teachers, administrators and students don't need to install any software, and various function modes are easy to use. Learners don't need to receive any training and all the functions are very easy. According to the modes and functions, administrators can empower management to learning group leaders to fulfill a level-to-level administration, which will make the system management more clear, humanizing and scientific. Administrators can perform the management only with simple training.

\subsection{Interface Design of M-Learning System}

OS M-learning system is combined with the principle of interface design of multimedia courseware; the main interface, the column interface and the media demo interface are designed and made according to the function modes of the system and the operation procedures. The main interface is shown in Figure 4(a), the Course Notice interface is shown in Figure 4(b) and the video/media display interface is shown in Figure 4(c).

\section{Conclusion}

M-learning is a learning mode which is close to the nature of learning, and it can not only be used as auxiliaries of remote learning but also an independent learning mode. In a society where the information and the network are highly developing, M-learning has become one of the most potential research orientations. In this paper, theories of M-learning are investigated and applications are simply experimented. By designing and developing the OS course M-learning system, more intuitive understandings of characteristics, development and technologies for M-learning resource development are obtained, which will strive for introducing the pervasive computing and mobile advantages into the education.

\section{Acknowledgements}

This work is sponsored by the Teaching Reform of Higher Education of Heilongjiang Province of China (Construction and Implementation of college mobile 


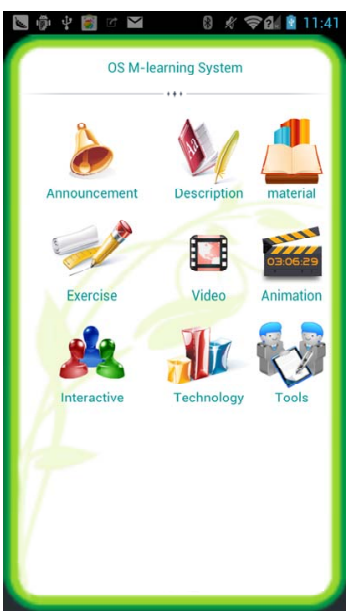

(a)

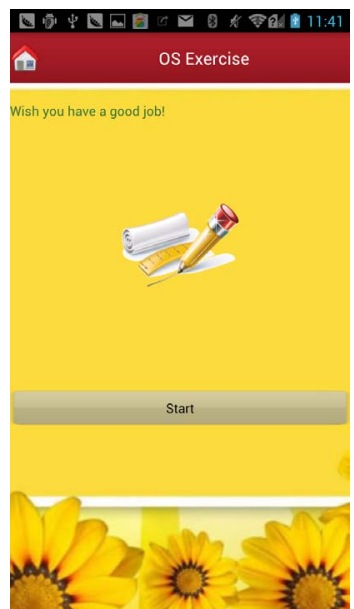

(b)

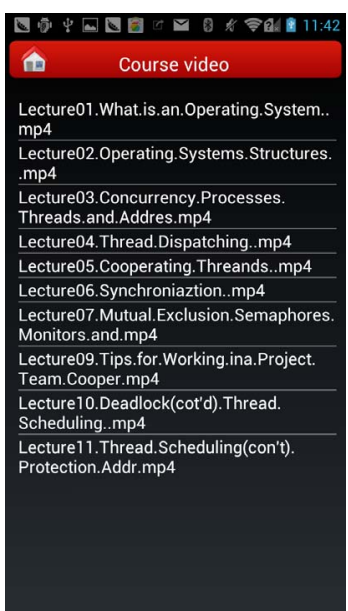

(c)

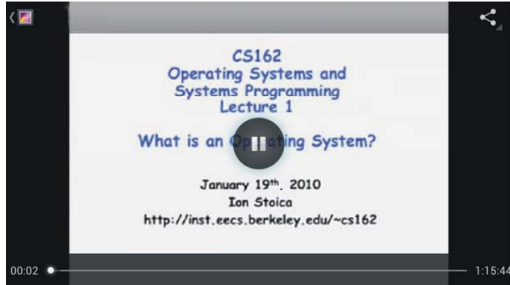

(d)

Figure 4. OS M-learning interface.

learning platform based on 3G technology: JG2012010 080) and Heilongjiang Province Educational and Scientific Project 2011 (Research on practical training mode of computer professional University and enterprise in alliance based on CDIO: GBC1211039).

\section{REFERENCES}

[1] L. Zhang, et al., "The Application of Mobile Learning in Higher Education Reform,” Computer Education, Vol. 6, 2010, pp. 34-38.

[2] G. Mellon, 2007. http://www.emu.edu/computing/wireless/

[3] A. Stone, J. Briggs and C. Smith, "SMS and Interactivity - Some Results from the Field, and Its Implications on Effective Uses of Mobile Technologies in Education," Proceedings of IEEE International Workshop on Wireless and Mobile Technologies in Education, Vaxjo, August 2002, pp. 147-151.

[4] J. Sariola, "What Are the Limits of Academic Teaching? In Search of the Opportunities of Mobile Learning." http://ok.helsinki.fi/tekstit/article.rtf

[5] S. Mike, C. Dan and W. Oliver, "The Design and Implementation of a Mobile Learning Resource." http://www.eee.bham.ac.uk/sharplem/Papers/mobile\%201 earnin-g\%20puc.pdf

[6] S. Mike, "The Design of Personal Mobile Technologies for Lifelong Learning.”
http://WWW.eee.bham.ac.uk/sharplem/Papers/handler\%2 0comped.pdf

[7] O. Smordal, J. Gregory and K. Langseth, "J: PDAs in Medical Education and Practice," Proceedings of IEEE International Workshop on Wireless and Mobile Technologies in Education, Vaxjo, August 2002, pp. 140-146.

[8] H. Ketamo, "xTask-Adaptable Working Environment," Proceedings of IEEE Internationa1 Workshop Wireless and Mobile Technologies in Education, Vaxjo, August 2002, pp. 55-62.

[9] Y. J. Liu, et al., "An Overall View of the Mobile Learning Domain,” Modern Educational Technology, Vol. 3, 2004, pp. 12-16.

[10] Y. C. Shi, W. K. Xie, G. Y. Xu, et al., "The Smart Classroom: Merging Technologies for Seamless Tele-Education,” IEEE Pervasive Computing, Vol. 2, No. 2, 2003, pp. 47-55. doi:10.1109/MPRV.2003.1203753

[11] W. N. Yue and A. Q. Dong, "Multimodal Chinese Characters Input for Handhelds,” Proceedings of the 5th Asia Pacific Conference on Computer Human Interaction, Beijing, 2002, pp. 652-658.

[12] J. S. Liu, "An Overall View of the Mobile Learning Status,” E-Education Research, Vol. 7, 2007, pp. 21-36.

[13] Y. E. Cheng, et al., "Mobile Learning and Its Theoretical Foundations," Open Education Research, Vol. 3, 2004, pp. 23-26. 